\title{
TECNOLOGIA AEROESPACIAL E DESESTRUTURAÇÃO SÓCIO-CULTURAL NAS COMUNIDADES QUILOMBOLAS DE ALCÂNTARA ${ }^{1}$
}

\author{
Maria do Socorro Gomes Araújo* \\ Domingos Leite Lima Filho**
}

"A aeronáutica vai às estrelas e deixa o povo no escuro"”

A implantação do Centro de Lançamentos de Alcântara - MA, iniciada em 1982, vem, desde então, provocando forte desestruturação sócio-cultural e violação de direitos no território étnico das comunidades negras rurais remanescentes de quilombos existentes naquela região.

O objetivo do presente texto é discutir esta problemática, a partir das observações de trabalhos de campo, realizados nestas comunidades da região de Alcântara, em 2004, e de pesquisa bibliográfica e documental. Os trabalhos de campo envolveram visitas in loco às comunidades quilombolas, cobertura fotográfica e entrevistas.

No desenvolvimento do trabalho, faremos inicialmente uma contextualização histórica da região e da formação socioeconômica e

* Graduada em História pela Universidade Federal do Piauí e especialista em Fotografia Artística pela Faculdade de Belas Artes de Salamanca (Espanha). Fotógrafa pesquisadora do GT Clóvis Moura - Paraná. (msocorroga@ig.com.br)

** Doutor em Educação pela Universidade Federal de Santa Catarina. Professor do Programa de Pós-Graduação em Tecnologia e do Departamento Acadêmico de Eletrotécnica da Universidade Tecnológica Federal do Paraná. (domingos@utfpr.edu.br)

1 Trabalho apresentado ao Seminário Presença Africana na Produção Social da Tecnologia no Brasil, PPGTE/UTFPR, Curitiba, 2 e 3 de dezembro de 2004.

2 Fala de um trabalhador quilombola, Alcântara - MA, alusiva à não existência de energia elétrica nas comunidades negras rurais remanescentes quilombolas localizadas no entorno do Centro de Lançamento Espaciais de Alcântara - MA. 
cultural das comunidades ali existentes, com enfoque particular para as populações negras, remanescentes de formações quilombolas. Em seguida, discutiremos aspectos conceituais ligados à questão das comunidades quilombolas no Brasil, destacando-se aí as categorias quilombos, terras de preto, terras de santo e território étnico. Na seqüência, trataremos brevemente da implantação do Centro de Lançamentos de Alcântara, e verificaremos os impactos deste empreendimento tecnológico espacial militar sobre a região, em especial as conseqüiências até aqui detectadas, as percepções que as comunidades quilombolas têm destes fatos, destacando ao final a importância de sua resistência em defesa de suas formações sócio-econômicas e de suas tradições étnico-culturais.

\section{A FORMAÇÃO HISTÓRICA E SOCIAL DAS COMUNIDADES DE ALCÂNTARA}

A região onde está o município, e nesta a base espacial militar do Centro de Lançamentos de Alcântara (CLA), tem muitos séculos de História. Chega-se a ela partindo do cais da Praia Grande, no centro da Cidade de São Luís, ilha em que se localiza a capital maranhense, e cruzando a Bahia de São Marcos, navegando na direção noroeste, até alcançar no porto do município, na margem continental, após os $22 \mathrm{~km}$ de travessia da bahia.

A formação histórica, socioeconômica e cultural da região onde hoje se localiza o município de Alcântara, inicia-se com seus habitantes nativos, os tupinambás, que se situavam nas regiões costeiras, e os tapuias que habitavam preferencialmente o interior. A região permaneceu praticamente inexplorada durante mais de um século de colonização portuguesa, até 1612, quando o navegador francês Daniel de la Touche, desembarca naquelas terras e estabelece na ilha do Maranhão - então denominada pelos nativos de Upaon-Açu (Ilha Grande), a França Equinocial. Somente a partir de então, os franceses, que há pelo menos duas décadas exploravam e traficavam madeira na região, resolvem estabelecer ali um primeiro núcleo habitacional e edificam o Forte de São Luís. ${ }^{3}$

3 A denominação dada a Fortaleza de Saint Louis em homenagem ao monarca francês Luis XIII com o tempo se estenderia ao próprio núcleo habitacional. 
Os franceses ali permaneceram até 1615 , quando então efetiva-se a reação e domínio da coroa portuguesa com a tomada do Forte de São Luís. Com isso, estabelece-se a colonização que passa a implementar um largo e sistemático processo de escravização, catequese jesuítica e aculturação das populações nativas.

A estratégia de povoamento e ocupação do território deu-se, inicialmente, com a chegada de ilhéus provenientes dos Açores e da Madeira, sob a forma de colonos livres, em expedições que desembarcam em São Luís entre 1617 e 1621 (JANEIRO e FERNANDES, 1989). Parte desta população irá, em seguida, deslocar-se da Ilha de São Luís ao continente, para a região onde então se encontrava a aldeia Tupinambá denominada Tapuitapera.

O desenvolvimento deste núcleo populacional evolui para a constituição da Freguesia de Tapuitapera, em 1622, que passa a ser importante ponto de apoio das rotas fluviais entre São Luís e Belém. Foi também base portuguesa utilizada na luta contra os holandeses invasores, entre 1641 e 1644. Em 1648 funda-se a Vila de Santo Antônio de Alcântara, estabelecendo-se ali características daqueles povos ilhéus, refletidas na arquitetura, religiosidade, festejos e culinária (MARTINS, 2004).

A economia da Vila tinha como ponto principal a plantação de canade-açúcar e algodão. A produção local organiza-se mediante a escravização indígena e africana, e constitui uma base para a exploração econômica da baixada maranhense, e do próprio abastecimento de São Luís, passando a ser um local propício para a fixação da aristocracia regional. Com isso, o núcleo urbano desenvolve-se com a construção de muitas edificações, dentre as quais se destacam a câmara, a igreja, o pelourinho e os armazéns do porto, pelo qual se estabelecia o comércio com São Luís.

$\mathrm{Na}$ Vila de Alcântara se instalaram por essa época diversas Ordens Religiosas: os Carmelitas e os Mercedários fundam um convento em 1651; e, um pouco mais tarde, já no início do Século XVIII, os Jesuítas ali estabelecem um colégio. Verificou-se, sobretudo entre os Carmelitas, a tentativa de introdução do sistema das "reduções" indígenas, utilizadas vastamente na América Espanhola nos séculos XVI e XVII (FERNANDES, 1998). 
O dinamismo e diversificação da produção exigem aporte de força de trabalho, para o que a escravização indígena era insuficiente e, por certas considerações, inadaptável. Isso determinou a necessidade de mão-de-obra escrava negra, proveniente da África e, de certo modo, inserida na própria atividade mercantil do tráfego negreiro supridora da expansão da produção açucareira e algodoeira no Brasil, nas Antilhas e na América do Norte.

As reformas pombalinas (1759) tiveram importante impacto na estrutura fundiária e produtiva locais, uma vez que as fazendas e propriedades dos jesuítas foram confiscadas e vendidas a particulares. É desse período também, a criação da Companhia Geral de Comércio do Maranhão e Grão-Pará, que contribuirá para a integração do Maranhão na exportação de produtos, principalmente o algodão, para a Inglaterra, no contexto do mercantilismo ascendente.

A partir de então se produz grande desenvolvimento em Alcântara, atingindo o apogeu por volta da metade do século XIX (anos 1850/60). Constata-se, no período, a existência de 81 fazendas de produtos agrícolas, 22 engenhos de açúcar, 24 fazendas de gado e mais de uma centena de salinas. A região é grande exportadora de produtos: $1^{\circ}$ lugar em sal; $2^{\circ}$ lugar, em açúcar, cachaça, couro e carne; $3^{0}$ lugar, em algodão, arroz, farinha e milho; $4^{\circ}$, em tapioca e peixe seco.

Este ciclo virtuoso será interrompido no terço final do século XIX, com a produção açucareira e de algodão em outras regiões e a queda dos preços internacionais destes produtos, as lutas de libertação e o fim da escravidão. Inicia-se um longo declínio econômico da região, que levou progressivamente ao abandono de fazendas e unidades produtoras, repassadas ao Estado ou à igreja, ou simplesmente desocupadas por seus senhores. Nesse mesmo período, as ordens religiosas dos Carmelitas e dos Mercedários também repassam suas propriedades à Diocese (igreja) ou ao Estado.

É justamente em parte destas terras abandonadas, na qual permaneceram os trabalhadores negros, escravos fugidos ou libertos, índios e mestiços, que se originam as comunidades camponesas tradicionais até hoje existentes. Estas populações, que se instalam nas antigas fazendas, nos mocambos, nas "terras de preto", ou nas "terras de santo", constituindo 
os vários quilombos ainda existentes ou as comunidades remanescentes quilombolas, praticam desde então uma organização social da produção baseada no campesinato comunal, no cultivo coletivo e livre, na produção complementar e na economia solidária e de trocas intercomunitárias de excedentes.

Do final do século XIX até o final do século XX, a região permaneceu praticamente sem interesse econômico ou sociocultural para o Estado, em âmbito nacional ou estadual. Por esta razão, o seu rico patrimônio históricocultural - com um dos mais pujantes conjuntos arquitetônicos coloniais e barrocos do Brasil e da América - ficou abandonado e em ruínas, alvo de depredações, furtos, espoliações e apropriações privadas, apesar de tombado como patrimônio nacional em 1948.

O município de Alcântara possuiu uma área de 114 mil hectares (50\% ocupada pelo CLA) e atualmente cerca de 20 mil habitantes, a maioria descendente de quilombolas e de indígenas, dos quais aproximadamente $80 \%$ vivem em comunidades distribuídas na zona rural. Estas populações dedicam-se às atividades produtivas de pesca, agricultura e extrativismo, que são praticadas de forma tradicional, tendo por base o trabalho coletivo comunal e artesanal.

Ao longo de mais de 250 anos de sua formação histórico-social e étnico-cultural, estas comunidades desenvolveram uma economia interligada, baseada no manejo sustentável da região: uma pescava, outra tecia rede, a terceira montava barcos, uma quarta fazia cerâmica, uma quinta plantava mandioca que era transformada em farinha pela sexta, etc, etc.

Estas comunidades vêm sendo, até os dias de hoje, as principais vítimas do processo de implantação do Centro de Lançamento Espaciais de Alcântara, desde que em 1979, ainda no período da ditadura militar, o Ministério da Aeronáutica anunciou o projeto e a necessidade de áreas da região para estes fins, concedida prontamente em 1980 com a de desapropriação de $520 \mathrm{~km}^{2}$, e o conseqüentemente deslocamento das populações e comunidades nela fixadas ancestralmente. Desde então estas comunidades resistem como podem, em condições extremamente precárias e desiguais, ante o poder estatal, do capital e da indústria bélica. Apesar do longo tempo já decorrido, o amplo conhecimento e posicionamento 
crítico da sociedade brasileira sobre o assunto ainda é muito incipiente. Ainda em 1981, o poeta e escritor Carlos Drumond de Andrade foi um dos primeiros a anunciar e protestar contra os impactos negativos e malefícios do empreendimento:

Qualquer pessoa que tenha um mínimo de sensibilidade em face das coisas de arte e história (os "bens culturais" que o governo procura não só defender como incitar a população a fazer o mesmo) arrepia-se ao ler que será instalada em Alcântara a segunda base de lançamentos de mísseis brasileiros. A área já começou a ser demarcada e um fato novo, surpreendente, bole com os nervos da pacata população da pacatíssima cidade inscrita nos livros de tombo do IPHAN como monumento nacional.

Claro que os foguetes não serão lançados no espaço ocupado pelo acervo arquitetônico e paisagístico da cidade, mas a proximidade dessa assustadora crer que os benefícios da circulação de dinheiro compensem os incômodos da militarização de vasta área agrícola em torno do conjunto tombado. Não se poderia localizar a estação de mísseis em outro ponto, sem afetar a grave e silenciosa Alcântara, com seus velhos sobrados convertidos em monumento nacional? ${ }^{4}$

Hoje, passados mais de vinte anos, os malefícios e os impactos sócio-econômicos e étnico-culturais negativos são muito maiores do que os prenunciados pelo poeta. Quanto aos benefícios que suposta e eventualmente trariam a circulação do capital e a militarização da região dificilmente se pode encontrá-los: o município possui apenas um hospital e uma escola de $2^{0}$ grau; a maioria das comunidades não possui luz elétrica; as estradas são precárias; a renda per capta é das mais baixas do país; o índice de analfabetismo é um dos maiores do Brasil, mesmo sendo um dos principais

4 Jornal do Brasil, 21 de junho de 1981, apud Comitê Universitário Contra a ALCA, Chega de foguetes e satélites... queremos viver aqui. Na terra. Editora ContrAlca, São Luiz, UFMA, s/data. 
pontos turísticos do Maranhão e contando, desde 1982, com uma Base Espacial de alta tecnologia.

\section{QUILOMBOS E QUILOMBOLAS: ALGUMAS QUESTÕES CONCEITUAIS}

No entorno da área desapropriada para o CLA, existem muitas comunidades rurais. Dentre elas nomeamos: Pirarena, Cajueiro, Marudá, Espera, Ponta Seca, Laje, Jenipaúba, Santo Antônio, Ponta Alta, Jabaquara, Peru, Titica, Santaninha, Cavem, Pedro Marinho, Santa Cruz, Aldeia, Capijuba, Santa Helena, São Francisco, Canelatiua, Pepital, Espera, Itapuaua, Iririzal, Ladeira, Só Assim, Itamatatiua, Itapera, Pirajuna, Alegre, Manuninha, Mato Grosso, Brito, Vista Alegre, Caiava, Baracatatiua, Mamuna, Santa Maria, Engenho, Retiro, São Paulo, Uru-Mirim, Tapera, Ponte do Murio e Uru-Grande.

Pela contextualização histórico-social e étnico cultural que realizamos anteriormente, quase a totalidade destas comunidades pode ser claramente identificada como comunidades negras rurais quilombolas. É importante, agora, alinharmos alguns elementos conceituais que definem os quilombos e as comunidades remanescentes.

$\mathrm{O}$ termo remanescente de quilombo indica a situação presente dos segmentos negros em diferentes regiões e contextos e é utilizado para designar um legado, uma herança cultural e material que lhe confere uma referência presencial no sentimento de ser e pertencer a um lugar específico. Este sentimento de pertença a um grupo e a uma terra é uma forma de expressão da identidade étnica e da territorialidade, construídas sempre em relação aos outros grupos com os quais os quilombolas se confrontam e se relacionam.

Entretanto, é bastante antiga a primeira definição em documento oficial que temos acerca do termo quilombo. Em resposta ao Rei de Portugal, em 1740, o Conselho Ultramarino definiu quilombo como "toda habitação de negros fugidos que passem de cinco, em parte despovoada, ainda que não tenham ranchos levantados nem se achem pilões neles"

5 In: A situação dos direitos humanos das comunidades negras e tradicionais de Alcântara. O direito à terra e à moradia dos remanescentes de quilombos de Alcântara, MA - Brasil. Relatório da Missão da Relatoria Nacional de Direito à Moradia Adequada e à Terra Urbana (2003). 
Esta definição do período colonial e imperial, que traz como pressuposto a formação de comunidades quilombolas somente a partir de escravos fugitivos e longe dos domínios da grande propriedade, chega aos nossos dias. No entanto,

é importante lembrar que houve escravo que não fugiu, que permaneceu autônomo dentro da grande propriedade e com atribuições diversas, houve aquele que fugiu e foi capturado e houve aquele que não pôde fugir porque ajudou os outros a fugirem e o seu papel era ficar (Relatório, 2003, p. 8).

Dessa forma, a garantia do direito à terra e os direitos daí decorrentes, trazida pela Constituição Federal de 1988, deve abranger todos os casos acima apresentados, com o seguinte teor:

Art. 68. Aos remanescentes das comunidades dos quilombos que estejam ocupando suas terras é reconhecida a propriedade definitiva, devendo o Estado emitir-Ihes os títulos respectivos (BRASIL, 1988).

Ao lado deste preceito, o governo do presidente Luís Inácio Lula da Silva deu um passo adiante nessa questão legal e conceitual pela edição do Decreto n. 4.887, de 20 de novembro de 2003, que "Regulamenta o procedimento para identificação, reconhecimento, delimitação, demarcação e titulação das terras ocupadas por remanescentes das comunidades dos quilombos de que trata o art. 68 do Ato das Disposições Constitucionais Transitórias". No referido Decreto lê-se:

Art. $2^{\circ}$. Consideram-se remanescentes das comunidades dos quilombos, para fins deste Decreto, os grupos étnico-raciais, segundo critérios de auto-atribuição, com trajetória histórica própria, dotados de relações territoriais específicas, com presunção de ancestralidade negra relacionada com a resistência à opressão histórica sofrida.

$\S 1^{\circ}$. Para fins deste Decreto, a caracterização dos remanescentes das comunidades dos quilombos será atestada mediante autodefinição da comunidade. 
$\S 2^{\circ}$. São terras ocupadas por remanescentes das comunidades dos quilombos as utilizadas para a garantia de sua reprodução física, social, econômica e cultural.

$\S 3^{\circ}$. Para a medição e demarcação das terras, serão levados em consideração critérios de territorialidade indicados pelos remanescentes das comunidades dos quilombos, sendo facultado à comunidade interessada apresentar as peças técnicas para a instrução procedimental (BRASIL, 2003).

A riqueza deste preceito constitucional (Artigo 68, CF 1988) e do dispositivo legal (Decreto n. 4.887/2003) é que buscam preservar exatamente o que é mais significativo da vida do quilombola: sua atividade permanente baseada em relações de ancestralidade de manejo sustentável da terra e de seus recursos naturais, com vistas a suprir indefinidamente sua subsistência material, social e cultural. Em síntese, a vida do quilombola é a própria vida da terra que habita.

Esta era a vida quilombola, dos milhares de Palmares espalhados pelo Brasil, descrita na singela estrofe de um cordel que, ao ressaltar o sonho de liberdade e a dureza da luta para conquistá-la, descreve também a beleza, fartura e alegria da vida nesses quilombos, com o que se homenageia os negros quilombolas que participaram da Guerra da Balaiada, uma das maiores revoltas populares ocorridas em nosso país, no Maranhão, entre 1838 e 1841 :

Esses negros organizados

Chamados de quilombolas

Viram na Balaiada

Que era chegada a hora

Da liberdade sonhada

Renascer naquela aurora.

Cosme bento das Chagas

Logo então se destacou 
E lá de Lagoa Amarela

Três mil negros libertou

E com tal valentia cega

A Balaiada engrossou.

\section{No quilombo da Lagoa Amarela}

A negada tudo tinha

Caça assada no espeto

Feijão, arroz e farinha

Água fria do Rio Preto

Ervas medicinais e mandinga (CRUZ, 1998).

Portanto, estas comunidades constituídas por terras de uso comum, com uma diversidade de apropriação dos recursos naturais (solo, hídricos, e florestais) em que diferentes categorias de trabalhadores e trabalhadoras rurais trabalham e mantêm a vida, reproduzindo práticas e saberes ancestrais e produzindo novos conhecimentos e formas de existência.

Fatores étnicos, de parentesco e de sucessão configuram um sistema político-organizativo, socioeconômico e étnico-cultural complexo e extremamente singular, com práticas e representações próprias. Esta base complexa estrutura a noção de territorialidade própria, que define a totalidade destas comunidades como um "território étnico" (ALMEIDA, 1988).

É importante atentar para as diferentes categorias de trabalhadores rurais e para as múltiplas formas pelas quais os quilombolas estabeleceram seu vínculo originário com a terra. Nesse sentido, referindo-se às origens das comunidades camponesas situadas na área em estudo, encravada entre a Baía de Cumã e a Bahia de São Marcos, ALMEIDA, apud DENÚNCIA (2001) destaca a constituição múltipla destas populações: "índios desaldeados, quilombolas, famílias de ex-escravos sob regime de aforamento, ex-escravos domésticos e demais moradores das fazendas de ordens religiosas e ex-escravos tornados herdeiros por força de disposições testamentárias e de atos de doação”. 
Estas distintas composições irão dar origem a denominações diversas, tais como as "terras de santo" e "terras de santíssimo", relativas às terras abandonadas pelas ordens religiosas. Quando a origem ocorre por doações a ex-escravos ou escravos libertos denomina-se "terras de preto", equivalente aos conceitos de quilombo ou "mocambo" (ALMEIDA, 1988).

As sucessivas gerações, transferências, apossamentos, relações de parentesco que se entrelaçam e promovem interpenetrações de domínio entre as diversas comunidades, com troca e compartilhamento de produções associadas, dão uma unidade socioecônomica e étnico-cultural a essas comunidades, formando um complexo social, isto é, a "territorialidade étnica" das comunidades negras rurais remanescentes de quilombos cujos domínios se estendem dentro e fora da área de terras expropriada pela Base Espacial de Alcântara (DENÚNCIA, 2001).

\section{O CENTRO DE LANÇAMENTOS DE ALCÂNTARA (CLA)}

Em 1982, foi constituído o Grupo para a Implantação do Centro de Lançamentos Alcântara (GICLA) ${ }^{6}$ e, no ano seguinte, foi criado o CLA com os objetivos de executar e apoiar as atividades de lançamentos e rastreamento de engenhos aeroespaciais. ${ }^{7}$

O Decreto Presidencial s/n., de 08 de agosto de 1991, declarou "de utilidade pública, para fins de desapropriação, áreas de terras e respectivas benfeitorias, na extensão de 62 mil hectares $(620 \mathrm{~km} 2)$, necessárias à implantação, pelo Ministério da Aeronáutica, do Centro de Lançamento De Alcântara”. Nesta área viviam, à época, cerca de 2000 famílias de trabalhadores rurais, distribuídas em inúmeras comunidades tradicionais, dentre aquelas que listamos anteriormente. ${ }^{8}$

Aáreafoi, inicialmente, dividida em duas: Área I, com aproximadamente 16 mil hectares, chamada de "área de segurança"; área II, o restante do território expropriado, destinado à construção de moradias de oficiais

6 Denominado inicialmente de Grupo para Implantação do Centro Espacial de Alcântara (GICEA).

7 Decreto n. 88.136, de 01 de março de 1983.

8 Existem estimativas que se referem a existência de 3600 famílias dentro da área destinada ao CLA (RELATÓRIO, 2003). 
militares, técnicos do CLA, um aeroporto e algumas das agrovilas ${ }^{9}$ para as quais seriam remetidas as comunidades que foram deslocadas.

As instalações do CLA foram edificadas na Área I, que compreende praticamente toda a parte litorânea do município. Nestas residiam 503 famílias, distribuídas em 48 comunidades, que sobreviviam essencialmente da pesca artesanal. Destas, 270 famílias de 21 povoados foram deslocadas para agrovilas, situadas em regiões não litorâneas. A Área II era habitada por cerca de 1500 famílias, e desta área também foram deslocadas algumas famílias, ainda na primeira fase e segunda fase de implantação do CLA. ${ }^{10}$ Em ambas as Áreas permanecem família e comunidades ameaçadas de deslocamento nas fases subseqüentes do projeto (DENÚNCIA, 2001).

Tanto as famílias já deslocadas, quanto as que resistem e as que estão ameaçadas de deslocamento forçado, se defrontam cotidianamente à tensão, coação, insegurança, restrição de circulação e de acesso aos recursos naturais da região e ameaças de cárcere.

O deslocamento forçado, a concentração de famílias em poucas áreas "artificiais" como as agrovilas e a restrição de acesso a outras áreas e a seus recursos destrói progressiva e aceleradamente a estrutura produtiva comunal, coletiva, associada, que mediante o rodízio e as trocas permitiam o manejo sustentável da região e a vivência em suas tradições culturais. É justamente esta ancestralidade do território étnico que está sendo destruída com a implantação da base aeroespacial do Centro de Lançamentos de Alcântara, conforme pode ser constatado pelo duro e cristalino depoimento de Lúcia Anastácia dos Santos, 67 anos, da Comunidade de Irizal:

\section{A Base não dá sossego, tá trazendo prejuízo. Antes tinha sururu, ostra, camarão. Veio o povo da agrovila e isso acabou.}

9 Agrovilas são núcleo habitacionais construídos pelo Ministério da Aeronáutica para receber as comunidades submetidas a deslocamento forçado, na qual as famílias foram alocadas em lote de terreno de $25 \mathrm{~m}$ x $40 \mathrm{~m}$, com casa de alvenaria e algumas edificações coletivas (escola, capela, centro de convivência e casa de farinha).

${ }^{10}$ As Fases III e IV, destinadas à adaptação do CLA para lançamento de veículos recicláveis de grande porte, está paralisada em virtude da tramitação no Congresso Nacional do Acordo de Salvaguardas entre Brasil e Estados Unidos. Prevê-se, nestas fases, o deslocamento forçado de cerca de 1500 habitantes, correspondendo à desocupação de 14 mil hectares (RELATÓRIO, 2003). 
E se tirarem a gente daqui? É o mesmo que tirar uma criança pequena da mãe. Meu pai e minha mãe nasceram aqui. Eles já morreram a mais de dez anos. Minha mãe dizia que na escravidão prendiam os escravos no pau e eles apanhavam, depois deitavam eles de barriga pro chão e pisavam em cima, como se fossem uma ponte. A estrada foi feita com nossos braços. A gente tem tambor de crioula, muita gente toca, aqui é a casa da festa. Nós cantamos, rezamos, tem Dia de Reis, é 6 de janeiro. Tem que dançar, que suar. Os homens batem tambor e s mulheres dançam. Essa era terra de engenho. Eles pagavam os escravos com farinha. Depois virou terra liberta, terra de santo, de santíssimo. Ou terra de preto, de quilombo. Antes tinha um bocado de peixe. Agora, com muita gente no lugar, tem falta. Temos medo, preocupação. (...) Nossa farinha é o pão da terra. Senão tiver farinha nós morremos. Temos banana, feijão, mandioca, milho, arroz. Trabalho na roça das 5 da manhã até 5 da tarde. A gente trabalha junto, os grupos na roça. Revezamos a terra (RELATÓRIO, 2003).

Assim como Irizal, temos na região de Alcântara inúmeras comunidades negras rurais quilombolas com tradições centenárias. Este é o caso, por exemplo, da Comunidade de Itamatatiua, onde habitam 80 famílias, que vivem da agricultura de subsistência de arroz, mandioca e milho. Uma das principais fontes de renda daquela comunidade é a cerâmica tradicional, desenvolvida por mulheres há mais de 300 anos, conforme o depoimento de Dona Neide de Jesus, ex-presidente da Associação de Mulheres de Itamatatiua. Há ainda a Associação dos Moradores Quilombolas de Santa Tereza D`Ávila de Itamatatiua. É uma comunidade de terra de santa, que tem como tradição religiosa o festejo de Santa Tereza, com ladainhas, toque de tambor de crioula, forró de caixa e dança de negros.

Decorrente do processo de implantação do CLA, iniciado em 1982 e que persiste até os nossos dias, ${ }^{11}$ as comunidades negras rurais remanescentes de quilombos vêm, desde então, sofrendo um amargo

${ }^{11}$ Mesmo o grave acidente ocorrido em 22 de agosto de 2003, quando ocorreu a explosão do Veiculo Lançador de Satélites (VLS 3) que destruiu a plataforma de lançamento e tudo ao seu redor em 
processo de desestruturação socioeconômica e étnico-cultural. Podemos constatar quatro situações distintas, conforme este processo desestruturante vai se aplacando sobre a vida dessas comunidades:

Deslocadas: comunidades que foram forçadas a deixar suas terras e foram deslocadas para "agrovilas" no período inicial de implantação do Centro de Lançamentos de Alcântara;

Ameaçadas de deslocamento: comunidades que estão na iminência de ser obrigadas a deixar suas terras por ocuparem a denominada “área de segurança” do Centro de Lançamento. Outras comunidades têm sido ameaçadas de deslocamento, caso seja aprovado o Acordo de Salvaguardas Tecnológicas, pelo qual o Brasil concede a utilização da Base para os Estados Unidos;

Ameaçadas de desestruturação: comunidades que estão na iminência de receber em suas áreas centenas de famílias provenientes das "comunidades ameaçadas de deslocamento". Isso iria gerar a desestruturação da cultura, da produção, dos recursos naturais e do modo de viver dessas comunidades;

Moradores da periferia: os que foram indenizados ou não e atualmente residem na periferia do município, deslocando-se para os locais de trabalho durante as diferentes etapas do ciclo agrícola ou cultivando as chamadas pontas de terra, áreas não submetidas ao controle dos chamados proprietários e do Ministério da Aeronáutica (Comitê Universitário Contra a ALCA, s.d., p. 13).

O processo causador dessa situação nas comunidades só foi possível porque apoiado na força do Estado, na lógica do poder e do capital, ferindo os dispositivos constitucionais e outros instrumentos legais e, sobretudo, materializando-se através da violação dos direitos das populações das

um raio de cerca de 50 metros, em circunstâncias que permanecem obscuras, provocando a morte de 21 técnicos do CLA, não foi capaz de produzir uma reflexão mais profunda do Estado brasileiro sobre os impactos sociais, a discriminação étnica e as violações de direitos provocadas por este empreendimento. 
comunidades remanescentes de quilombos e tradicionais de Alcântara. A Relatoria do Direito à Moradia e a Terra Urbana, realizada em 2003, tipificou as seguintes violações de direitos:

- direito a cidades sustentáveis;

- direito à moradia;

- direito cultural;

- direito à propriedade;

- direito à alimentação;

- direito ao trabalho;

- direito à igualdade / direito de não ser discriminado;

- direito de assistência jurídica integral e gratuita;

- direito à participação política e exercício da cidadania.

\section{CONSIDERAÇÕES FINAIS: A RESISTÊNCIA CONTRA O CLA É PARTE DA LUTA PELOS DIREITOS DOS QUILOMBOLAS}

A pesquisa bibliográfica e os dados de campo levantados nas diversas comunidades negras rurais remanescentes de quilombos da região de Alcântara - MA possibilitaram produzir uma aproximação à história e ao cotidiano presente, representados nas práticas e objetos de trabalho, práticas e cânticos de lazer e trabalho, costumes, saberes e fazeres, alimentos e culinária, rezas, crendices e religiosidade, destacando a significação dessas expressões como práticas de identidade, afirmação e resistência cultural. Através dessas múltiplas dimensões ficou revelada a desestruturação socioeconômica e étnico-cultural que, desde 1982, vem sendo provocada pela implantação do Centro de Lançamentos de Alcântara, baseado num processo continuado de violações dos direitos dessas populações.

O trabalho também evidenciou a importância das práticas ancestrais realizadas por essas comunidades na preservação ambiental e no manejo 
sustentável dos recursos naturais nos quais as comunidades quilombolas estão inseridas, destacando a importância de sua preservação como forma de garantia da qualidade de vida autônoma, sustentável e comunitária que revelam a força e influência da cultura de origem africana na formação social do Maranhão e do Brasil.

Para um aprofundamento acerca das categorias "terra de preto e terra de santo”, cfr. ALMEIDA, Alfredo Wagner Berno. Terras de Preto, Terras de Santo, Terras de Índio: posse comunal e conflito. Humanidades, ano IV, n.15, Brasília: UNB, 1988.

\section{REFERÊNCIAS}

ANJOS, Rafael Sanzio Araújo. Territórios das comunidades remanescentes de antigos quilombos no Brasil - primeira configuração espacial. Brasília: Mapas, 2000.

BRASIL. Constituição Federal de 1988. Brasília: 1988.

BRASIL. Decreto n. 4.887, de 20 de novembro de 2003. Brasília, 2003.

COMITÊ Universitário contra a ALCA. Chega de foguetes e satélites... queremos viver aqui. Na terra. São Luís: ContrAlca, s/d.

CRUZ, Magno José. A epopéia dos guerreiros balaios na versão dos oprimidos. In: A guerra da Balaiada. Centro de Cultura Negra do Maranhão e Sociedade Maranhense de Direitos Humanos. São Luís: Coleção Negro Cosme, 1998.

DENÚNCIA contra o Estado Brasileiro. Os representantes das Comunidades de Samucangaua et Alli. São Luís: mimeo, 2001.

FERNANDES, Carlos Aparecido. Deslocamento Compulsório de Trabalhadores Rurais: o caso do Centro de Lançamento de Alcântara, mimeo. São Luís: UFMA, 1998.

JANEIRO, Maria de Lourdes e FERNANDES, José Manoel. Um percurso 
da arquitetura açoriana - do arquipélago ao Brasil. In: Anais da 2a. Semana de Estudos Açorianos. Florianópolis: UFSC, 1989.

MARTINS, A. Municípios de São Luís e Alcântara no Maranhão: informes preliminares de formação e função. www.historiadomaranhaonanet. hpg.ig.com.br, acesso em 11.08.2004.

RELATÓRIO da Missão da Relatoria Nacional do Direito à Moradia Adequada e à Terra Urbana. A situação dos direitos humanos nas comunidades negras e tradicionais de Alcântara. São Paulo: Instituto Polis, 2003. 
